\title{
Isolation and enhancement of resveratrol production in Xylaria psidii by exploring the phenomenon of epigenetics: using DNA methyltransferases and histone deacetylase as epigenetic modifiers
}

\author{
Vagish Dwibedi $^{1} \cdot$ Shreya Kalia ${ }^{1} \cdot$ Sanjai Saxena ${ }^{1} \mathbb{D}$ \\ Received: 11 February 2019 / Accepted: 6 May 2019 / Published online: 13 May 2019 \\ (c) Springer Nature B.V. 2019
}

\begin{abstract}
Resveratrol is an important stilbene which is having a high demand due to its therapeutic, cosmeceutical and nutraceutical activities. The current study mainly focuses on strategies to enhance the fungal potential to produce resveratrol via the activation of the cryptic biosynthetic pathway with their particular interest in the antioxidant application. The endophytic fungus Xylaria psidii was isolated from the surface sterilized leaf of Vitis vinifera. With the help of HPLC analysis it is found that resveratrol concentration was maximum and enhanced in case of treatment with $5 \mu \mathrm{m}$ SAHA $(52.32 \mu \mathrm{g} / \mathrm{mL})$ and by $10 \mu \mathrm{m}$ AZA $(48.94 \mu \mathrm{g} / \mathrm{mL})$ followed by $10 \mu \mathrm{m}$ SAHA $(41.10 \mu \mathrm{g} / \mathrm{mL})$ and $5 \mu \mathrm{m}$ AZA $(37.72 \mu \mathrm{g} / \mathrm{mL})$. After treatment with different concentration of epigenetic modifiers such as HDAC inhibitors (SAHA) and dMNTs (AZA) inhibitors, a significant increase in antioxidant potential was obtained. In the case of DPPH increase in scavenging potential was found as compared to wild strain. Treatment with $5 \mu \mathrm{m}$ SAHA and by $10 \mu \mathrm{m}$ AZA was showing strong antioxidant potential among all the epigenetic variants as compared to wild strain. In the case of TEAC also the same trend as in the case of DPPH was obtained.
\end{abstract}

Electronic supplementary material The online version of this article (https://doi.org/10.1007/s11033-019-04862-z) contains supplementary material, which is available to authorized users.

Sanjai Saxena

sanjaibiotech@yahoo.com; ssaxena@thapar.edu

1 Department of Biotechnology, Thapar Institute of Engineering and Technology, Patiala, Punjab, India 


\section{Graphical abstract}

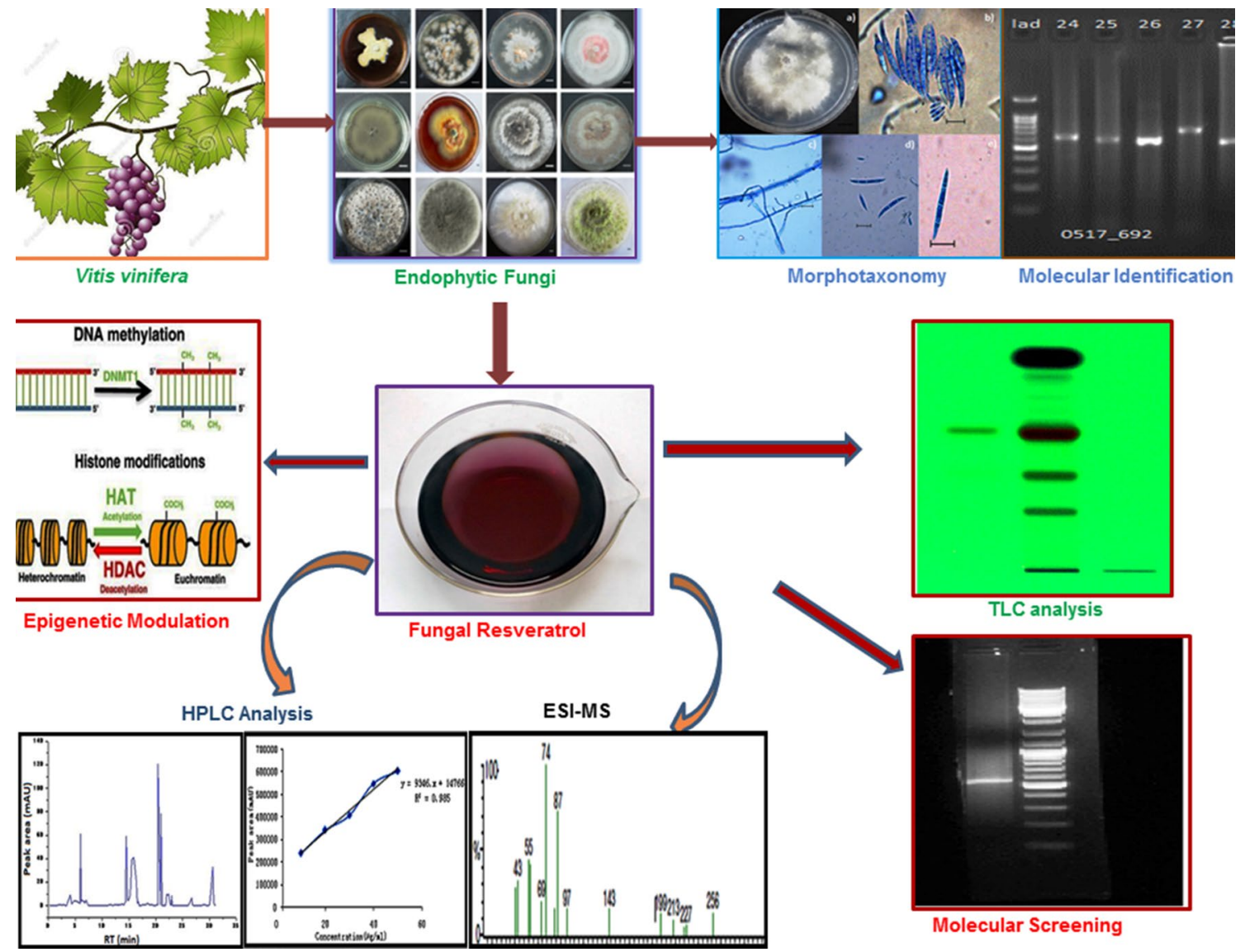

Keywords Endophytic fungi $\cdot$ Resveratrol $\cdot$ Epigenetic modification $\cdot$ HPLC $\cdot$ Xylaria psidii

\section{Abbreviations}

DPPH 2,2-Diphenyl-1-picrylhydrazyl

TEAC Trolox equivalent antioxidant capacity

FRAP Ferric reducing antioxidant power

TPC Total phenolic content

TFC Total flavonoids content

RESV Resveratrol

MHA Muller Hinton agar

SDA Sabouraud dextrose agar

MTCC Microbial type culture collection

ATCC American type culture collection

Sau Staphylococcus aureus

\section{Introduction}

Resveratrol (RESV) is a natural polyphenol of stilbene family which is represented by two benzene rings associated via isopropyl moiety separated by a double bond [1]. Resveratrol was first discovered in the 1940s from the roots of Veratrum grandifolium (White hellebore) and subsequently in 1960s from Polygonum cuspidatum which were traditionally used as a component of Chinese and Japanese medicines [2, 3]. However, the medicinal properties of resveratrol came into the limelight when it was observed that the French people exhibited very few symptoms of coronary heart diseases despite French cuisine comprising a large number of saturated fats. This observation was termed as "French paradox". Subsequently, the presence of resveratrol in the red wine was attributed for the cardioprotective action [4]. In addition to various properties like anti-cancer, anti-inflammatory, antidiabetic, anti-aging [5, 6]; RESV has made a spot for itself in agriculture, medicine, food and cosmetic industry as a boon molecule. RESV also possess an unusual antifungal activity against Botrytis cinerea which is the most important fungal pathogen of grape vines [7]. These outstanding properties of resveratrol make it a molecule of high appeal among researchers ever since its discovery.

Various sources of resveratrol comprise of grapes, peanuts, chocolate, tea and other berry species [8]. Currently, 
RESV is commercially extracted from the roots of Polygonum cuspidatum, which is expensive as well as time-consuming process. Moreover, this may also have a negative ecological impact since the extensive annihilation of the plant is carried out. Many techniques have been employed for the enhancement of secondary metabolite production like plant cell culture technology wherein cells are cultivated in bioreactors to produce a secondary metabolite using hairy root culture, rol, and STS gene transformation $[9,10]$. However, the significant disadvantage of this technique is genomic instability which leads to the silencing of various other gene clusters [11]. As there is global demand for RESV molecule, it has become imperative to explore alternative methods for bulk production of RESV.

Endophytic fungi are a particular class of fungi which resides inside the plant tissue and maintain an asymptomatic and inconspicuous union with their hosts, minimum for a season of their life cycle. Endophytic fungi exhibit an exciting property of producing compounds analogous to those present in the host plant as a result endophytes are today recognized as an essential source for the production of various medicinal molecules of plant origin for direct use as a drug [12]. Various techniques are these days employed on endophytes to target the enhancement of the secondary metabolite production like pathogen attack, UV irradiation, and genetic modification using STS genes or rol genes [13, 14] or by using biosynthetic precursor or chemical elicitors.

Epigenetics allows us to target a large number of fungi without any prior knowledge of their genome. Therefore, epigenetic modulators can be used as a strategy to epigenetically regulate the gene transcription of endophytic fungi. An epigenetic modification like histone deactivation and DNA methylation controls the putative biosynthesis of gene clusters [15]. Therefore, epigenetics can be utilized as a strategy for modulating the gene expression and enhancing the production of a target secondary metabolite. Chemical elicitors like suberoylanilide hydroxamic acid (SAHA) and 5-azacytidine (AZA) which causes hypomethylation and histone deacetylation respectively, have been used to target biosynthetic pathways. AZA induces hypomethylation of the DNA by inhibiting DNA methyltransferase (DNMT) enzyme which catalyses the transfer of methyl group to the DNA apart from getting incorporated into the genetic material which leads to the disassembly of polyribosomes, defective methylation and acceptor function of tRNA thereby inhibiting production of specific proteins $[15,16]$. SAHA acts as histone deacetylase inhibitor which by acting as a chelator for zinc ions present in the active site of the histone deacetylase leads to the accumulation of the acetylated histones and acetylated protein further inhibiting the gene expression $[17,18]$.

Thus, in the present work, we report an endophytic fungus \#22(P) VVLPM as a promising candidate for the production of resveratrol and also intend to enhance resveratrol production by developing epigenetic variants of endophytic fungus \#22(P) VVLPM having high titer value of RESV in free fermenting conditions.

\section{Materials and methods}

\section{Instrumentation and reagents}

HPLC analysis was carried out using Perkin Elmer HPLC (Series 200) with C-18 reverse phase Discovery column (4.6 mm ID $\times 150 \mathrm{~mm} \mathrm{~L}$; Sigma Aldrich) for the determination of resveratrol content. BIOTEK $®$ Powerwave 340 microplate reader was used for different anti-oxidant assays. Resveratrol (RESV), 2,2'-azino-bis (3-ethyl benzothiazoline6-sulphonic acid (ABTS), Trolox and FC reagent was purchased from TCI (Japan); 2,2-diphenyl-1-picrylhydrazyl (DPPH), Streptomycin, Sodium sulphate $\left(\mathrm{Na}_{2} \mathrm{SO}_{4}\right)$, Aluminium chloride $\left(\mathrm{AlCl}_{3}\right)$, Ferric chloride $\left(\mathrm{FeCl}_{3}\right)$ from HiMedia Labs Pvt. Ltd. (India). Methanol ( $\mathrm{MeOH})$, Acetonitrile (ACN) and Conc. Sulphuric acid $\left(\mathrm{H}_{2} \mathrm{SO}_{4}\right)$ from Merck, Millipore, (USA), a Nitrocellulose membrane (NCM) from GE Healthcare and Life Sciences (USA), Orthophosphoric acid $\left(\mathrm{H}_{3} \mathrm{PO}_{4}\right)$ from Hi-Media (India).

\section{Isolation of fungal endophytes and their preservation}

Healthy, mature, symptomless leaves were collected from the wine of Vitis vinifera from the National Center for Grapes, Pune Maharashtra. The collected leaves were stored in sterile zip pouches and stored at $4{ }^{\circ} \mathrm{C}$. The collected sample was washed thoroughly under running tap water for 20-30 min and then washed with double distilled water to remove external debris. Subsequently, the leaf and stem samples were surface sterilized by dipping them in $2 \%$ solution of sodium hypochlorite for 5 min followed by $70 \%$ ethanol for $45 \mathrm{~s}$, followed by dipping in $30 \%$ ethanol for the $30 \mathrm{~s}$ and drying them aseptically. Finally, $5 \times 5 \mathrm{~mm}$ segments from the sterilized leaves were placed on Potato Dextrose Agar (PDA) [19]. The potency of surface sterilization of leaves was analyzed by a leaf imprint method $[19,20]$. The plates were then incubated at $28 \pm 2{ }^{\circ} \mathrm{C}$ for 10 days with $12 \mathrm{~h}$ light and $12 \mathrm{~h}$ dark cycles. Emerging hyphae after 14 days incubation were picked and transferred on PDA for further analysis. Pure cultures of the endophytic fungi so obtained were stored on PDA slants enriched with $10 \%$ glycerol.

\section{Culture filtrate production}

The endophytic isolate \#22(P) VVLPM was subjected to culture filtrate production by inoculating $5 \mathrm{~mm}$ fungal mycelial disc of 8-10 day old fungal culture to $50 \mathrm{~mL}$ pre-sterilized 
Potato dextrose broth (PDB) medium in $250 \mathrm{~mL}$ Erlenmeyer flasks. The flasks were then incubated at $28 \pm 2{ }^{\circ} \mathrm{C}, 120 \mathrm{rpm}$ for 10 days. After the incubation, the spent broth was separated from mycelia by filtration through Whatman filter paper 4 followed by centrifugation at 15,000 rpm for $5 \mathrm{~min}$ and then passing it through $0.2 \mu \mathrm{M}$ nitrocellulose membrane to get cell-free filtrate [21-23].

\section{Liquid-liquid extraction and TLC analysis}

The fungal filtrate and ethyl acetate were taken up in a ratio of 1:3 and extracted three times. The organic layers so obtained were pooled and dehydrated by addition of anhydrous sodium sulphate. Subsequently, the solvent fraction was evaporated in a rotary evaporator at $30{ }^{\circ} \mathrm{C}$ to dryness to get the coarse fraction. The coarse fraction of the cultures was further fractionated by subjecting to preparative thin layer chromatography (PTLC). The TLC plate of $0.5 \mathrm{~mm}$ thickness was prepared by coating silica gel (Sigma Aldrich; 381276 ) onto $20 \times 15 \times 5 \mathrm{~mm}$ clean glass plates (Merck Millipore; RP-8F254S) which was activated by incubating at $100{ }^{\circ} \mathrm{C}$ for $2 \mathrm{~h}$ before use. Subsequently, the sample was spotted onto activated TLC plate just $1 \mathrm{~cm}$ above the edge of the plate with the help of capillary tube (Sigma Aldrich; Z114960). Simultaneously, the TLC chamber was saturated with different solvent systems (binary/tertiary) for $30 \mathrm{~min}$. The TLC plate with the sample was then placed inside the saturated TLC chamber and allowed to run for $30 \mathrm{~min}$ when the solvent front reached the marked level. Subsequently, the TLC plate was taken out and allowed to air dry. The chromatogram was developed by visualizing the TLC plate under UV light (Thermo Fisher Scientific; UVGL-58). Resveratrol $(0.1 \mathrm{mg} / \mathrm{mL})$ was used as the standard for the comparison of retention factor $\left(R_{f}\right)$ value. The $R_{f}$ value of each band was obtained as the ratio of distance moved by solute to that of solvent [23, 24].

\section{High-performance liquid chromatography (HPLC)}

The stock solutions of standard resveratrol, fungal crude extracts and AZA, SAHA treated samples were prepared $(0.1-1 \mathrm{mg} / \mathrm{mL})$ and $1 \mathrm{mg} / \mathrm{mL}$ of methanol respectively and stored in dark and cool place to avoid the oxidation and isomerisation of trans-resveratrol to cis form. Subsequently the samples were sonicated for $15 \mathrm{~min}$, followed by filtration through a syringe filter with cellulose membrane of $0.22 \mu \mathrm{m}$ (GE Healthcare and Life Sciences, Merck, Millipore USA). The identification and concentration of RESV in crude bioactive fractions was determined via HPLC (PerkinElmer-200, USA) using C18 reverse phase discovery column (Sigma Aldrich, USA) equipped with series -200 pump, dual wavelength detector, and total chrome workstation software. About, $20 \mu \mathrm{L}$ of the sample of defined concentration was injected into the HPLC column and eluted using orthophosphoric acid (0.1\%, pH 2.3, Sigma Aldrich, USA) and acetonitrile (Sigma Aldrich, USA), 45-55\% ratio was used as mobile phase with a flow rate of $1 \mathrm{~mL} / \mathrm{min}$. The yield of fungal RESV was determined against a standard curve of standard RESV $(0.1-1 \mathrm{mg} / \mathrm{mL})$ under similar conditions. The peak area versus concentration of the standard as well as the number of peaks and peak height were used to estimate the concentration of resveratrol [22, 23, 25].

\section{LC-MS analysis}

The residue of fungal resveratrol from Xylaria psidii and standard resveratrol were analyzed by LC-MS (Waters, Micromass Q-TOF micro using Waters Alliance 2795 separation module) to confirm the presence of resveratrol. The confirmation was done on the basis of molecular ion of standard and fungal resveratrol by comparing their molecular ions as well as the fragmentation pattern [26, 27].

\section{Morphotaxonomy of resveratrol producing endophytic fungus}

For morphotaxonomic studies, the endophytic fungi were grown over different media i.e., Water agar (WA), Czapek Dox Agar (CDA), Grape leaf agar (GLA), Potato Dextrose Agar (PDA), Cornmeal agar (CMA), Fusarium minimal media (FMA), Synthetic nutrient deficient agar (SNA) for 30 days at $28 \pm 2{ }^{\circ} \mathrm{C}$ and $98 \%$ relative humidity (with $12 \mathrm{~h}$ of photoperiod). Colony growth rate, appearance, along with its microscopic features like hyphae characteristics, conidia formation, and other cellular bodies were critically observed under Nikon stereo zoom microscope (Nikon, Japan). All the micrometric observations were carried out using Nikon NIS element software with at least 30 observations per structure [28-30].

\section{Molecular identification of the resveratrol producing endophytic fungus}

For genomic DNA extraction, mycelia of 3-4 days old culture (approx. 0.1-0.2 g) was scraped off with the sterile inoculation loop and crushed to excellent powder in a sterile mortar and pestle under liquid nitrogen. Further DNA extraction was done by using the Wizard Genomic DNA purification kit (Promega, Madison, WI) as per manufacturer's instructions. The Internal Transcribed Spacer (ITS) region $1,5.8 \mathrm{~S}$ and 2 was amplified using ITS 1 and ITS 4 primers [31]. The reaction mixture $(25 \mu \mathrm{L})$ comprised of $1.5 \mathrm{U}$ of Taq DNA Polymerase in $10 \times$ Taq buffer containing $25 \mathrm{mM} \mathrm{MgCl}{ }_{2}$ (Bangalore GeNei, Bengaluru, India), $2.5 \mathrm{mM}$ of dNTP, $1 \mu \mathrm{L}$ of extracted genomic DNA, $10 \mathrm{mM}$ of each primer. The conditions for the polymerase chain 
reaction were $96{ }^{\circ} \mathrm{C}$ for 5 min followed by 39 cycles of $95{ }^{\circ} \mathrm{C}$ for $45 \mathrm{~s}, 60{ }^{\circ} \mathrm{C}$ for $45 \mathrm{~s}, 72{ }^{\circ} \mathrm{C}$ for $45 \mathrm{~s}$ followed by final extension at $72{ }^{\circ} \mathrm{C}$ for $10 \mathrm{~min}$. The ITS amplicons so obtained were examined using a $1.5 \%$ agarose gel under UV light in Bio-Rad Gel documentation System using Quantity 1-D analysis software (Bio-Rad, Hercules, CA). The PCR products were purified with Wizard SV gel and PCR cleanup system (Promega, Madison, WI) as per manufacturer's instructions. The obtained PCR products were sequenced at Eurofins (Bangalore, India).

The final sequence was then obtained by assembling the sequences using Sequencher ver.5 (www.genecodes.com) and submitted to the GenBank under the accession number MH142837. The sequence similarity search of the ITS sequence was performed using the BLAST algorithm tool of NCBI. The selected sequences of reference taxa obtained using BLAST were then aligned with the ITS sequence of the endophytic fungi using the Clustal W option in MEGA 6 . The aligned sequences were trimmed to make alignment uniform, and the aligned files were saved in FASTA and MEGA format. The evolutionary relationship was inferred by employing the Maximum Likelihood method using Tamura and Nei Model [32]. A thousand bootstraps were used to assess the evolutionary history. Gaps were considered as missing data.

\section{Induction of epigenetic modulation using chemical elicitors}

\section{Preparation of AZA and SAHA PDA plates of Xylaria psidii}

The wild-type endophytic fungus Xylaria psidii was subjected to epigenetic modulation using 5-azacytidine (AZA) and suberoylanilide hydroxamic acid (SAHA) as chemical elicitors. The stock solutions of $1 \mathrm{mg} / \mathrm{mL}$ of AZA and SAHA were prepared in DMSO. The PDA plates enriched with different concentration of AZA and SAHA ranging from $1 \mu \mathrm{M}, 3 \mu \mathrm{M}, 5 \mu \mathrm{M}, 10 \mu \mathrm{M}, 20 \mu \mathrm{M}, 30 \mu \mathrm{M}, 40 \mu \mathrm{M}$, $50 \mu \mathrm{M}, 60 \mu \mathrm{M}, 70 \mu \mathrm{M}, 80 \mu \mathrm{M}, 90 \mu \mathrm{M}, 100 \mu \mathrm{M}$ respectively were prepared and the plates were allowed to solidify at the room temperature. The plates were stored in an incubator till further use at the temperature of $28 \pm 2{ }^{\circ} \mathrm{C}$.

The endophytic fungus \#22(P) VVLPM was point inoculated at the center of the AZA and SAHA enriched PDA plates respectively at the concentrations mentioned above. The plates were then incubated at $28 \pm 2{ }^{\circ} \mathrm{C}$ for 10 days.

\section{Production of culture filtrates and culture filtrate extraction and biomass calculation}

For resveratrol production, $50 \mathrm{~mL}$ of pre-sterilized potato dextrose broth (PDB, HiMedia, India) in $250 \mathrm{~mL}$ Erlenmeyer flask (Borosil, India, 4980021) was aseptically inoculated with a $5 \mathrm{~mm}$ mycelial disc of a week old fungal culture. The flask was then incubated at $28 \pm 2{ }^{\circ} \mathrm{C}, 120 \mathrm{rpm}$ for 10 days. After the culmination of the incubation period, the mycelium was separated from the spent broth by filtration through Whatman paper 4 (Sigma Aldrich, USA, Z240567) followed by centrifugation at $15,000 \mathrm{rpm}$ for $5 \mathrm{~min}$ and then passing it through the $0.2 \mu \mathrm{m}$ nitrocellulose membrane (Merck Millipore, USA, PR04066) for making it cell-free. Further, the biomass of fungal spores was jotted down, for which the filter paper containing fungal spores was dried at $60^{\circ} \mathrm{C}$ for overnight in a hot air oven, and the weight of dried spores was calculated by subtracting from the pre-observed weight of filter paper.

\section{Biological assays}

\section{DPPH scavenging assay}

The free radical scavenging activity of the culture filtrate of \#22(P) VVLPM AZA and SAHA epigenetic variants was determined using DPPH (1,1-diphenyl-2-picrylhydrazyl) radicals, according to the procedure described in the literature [33] with minimal modifications. Briefly, $20 \mu \mathrm{L}$ of the culture filtrate was added to $230 \mu \mathrm{L}$ of DPPH $(100 \mu \mathrm{M}$ in methanol) and mixed thoroughly. The mixture was incubated for $30 \mathrm{~min}$ at room temperature in the dark. After incubation, the absorbance was measured at $517 \mathrm{~nm}$ using BIOTEK® Powerwave 340 microtiter plate reader. Working DPPH used as positive control and methanol as a negative control. Resveratrol $(10-50 \mu \mathrm{g} / \mathrm{mL})$ was used as a standard. The test was performed in triplicate, and the data were reported as mean \pm SD. Percentage of free radical scavenging (\%FRS) at different concentration was calculated using the formula:

$\%$ Free radical scavenging $=\frac{(\text { ODcontrol }- \text { ODsample })}{\text { ODcontrol }} \times 100$

\section{Trolox equivalent antioxidant assay (TEAC)}

TEAC was analyzed by using the method described by Re et al. [34]. The assay utilizes the ability of an antioxidant to scavenge $\mathrm{ABTS}^{+}$. To determine the level of its activity ABTS radical was generated by mixing $7 \mathrm{mM}$ ABTS (2,2'-azino-bis-3-ethylbenzothiazoline 6-sulphonic acid) (TCI, Japan) dissolved in 0.1 M PBS of pH 7.4 and $2.45 \mathrm{mM}$ potassium persulphate in $1: 1$ and incubated for $16 \mathrm{~h}$ at room temperature in the dark. This ABTS mixture was diluted in PBS to an absorbance of $0.9-1.0$ at $734 \mathrm{~nm}$ using BIOTEK ${ }^{\circledR}$ Powerwave 340 microtiter plate reader. To carry out the reaction $1 \mathrm{~mL}$ of working ABTS solution was added to $10 \mu \mathrm{L}$ of the extract and the reaction mixture was allowed to stand for $6 \mathrm{~min}$. The decrease in absorbance was recorded at $734 \mathrm{~nm}$. Phosphate buffer saline was used as a blank, 
and ABTS was used as a control. The test was performed in triplicate, and the data were reported as the mean \pm SD (Standard deviation). Percentage of free radical scavenging (\%FRS) at different concentration was calculated using the formula.

$\%$ Free radical scavenging $=\frac{(\text { ODcontrol }- \text { ODsample })}{\text { ODcontrol }} \times 100$

\section{Stability study of epigenetic variant}

The epigenetic variants were sub-cultured up to five generations on AZA and SAHA enriched PDA plates in which the maximum RESV concentration appeared during HPLC analysis of the first epigenetic variants. Subsequently the stability of the variants was also evaluated using HPLC and different in vitro antioxidant assays.

\section{Statistical analysis}

All the assays were performed in triplicates, and the data were represented as mean \pm standard deviation. The results were analyzed by ANOVA followed by Tukey post hoc test $(\mathrm{p}<0.05)$. Statistical analysis was performed using Graph Pad Prism 7 software and $p<0.05$ was considered significant.

\section{Results}

\section{Isolation and preservation of endophytic \#22(P) VVLPM}

In the present study, an endophytic fungus was isolated from the surface sterilized leaves of Vitis vinifera (Shiraz) from the Pune, Maharashtra. Culture isolate was preserved on PDA slants and vials supplemented with $10 \%$ (w/v) glycerol and incubated at $26 \pm 2{ }^{\circ} \mathrm{C}$ for the growth and stored at $4{ }^{\circ} \mathrm{C}$ for maintenance of culture.

\section{Sub culturing of \#22(P) VVLPM on AZA and SAHA PDA plates}

The fungal isolates of \#22(P) VVLPM inoculated on the PDA plates supplemented with different concentration of AZA and SAHA, produced variation in the morphological characteristics of \#22(P) VVLPM (Fig. 1). Changes in colony diameter of the subcultured \#22(P) VVLPM over PDA plates with different concentrations of AZA and SAHA were noted after the incubation of 10 days (Fig. 1). It was observed that the diameter of the colony decreased after the concentration of $20 \mu \mathrm{M}$ of AZA and SAHA due to the toxicity at higher concentrations (Fig. 1).

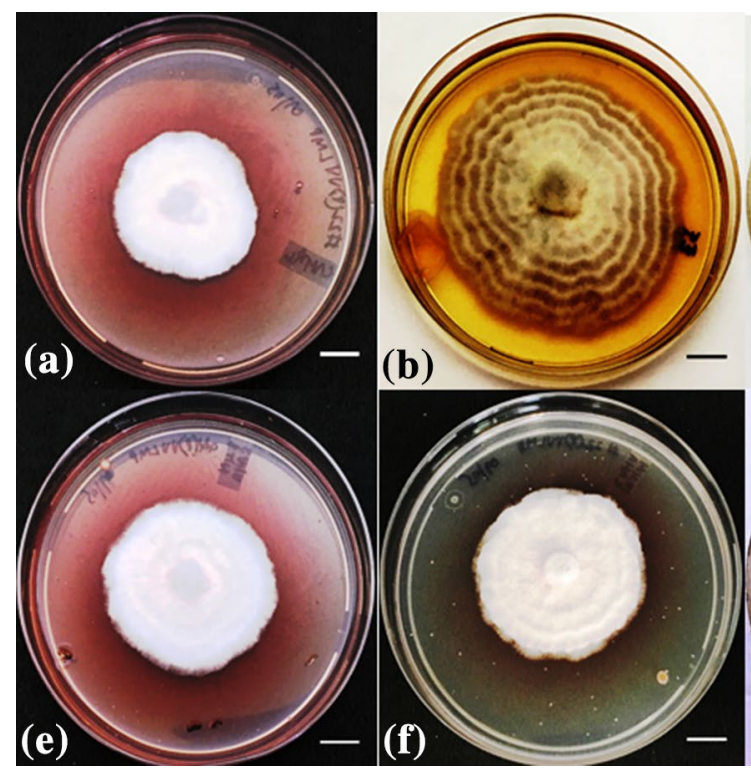

Fig. 1 Epigenetic variants of \#22(P)VVLPM a Control (\#22(P) VVLPM); b AZA $10 \mu \mathrm{m}$ on PDA medium; c AZA $20 \mu \mathrm{m}$ on PDA medium; d AZA $60 \mu \mathrm{m}$ on PDA medium; e SAHA $1 \mu \mathrm{m}$ on PDA

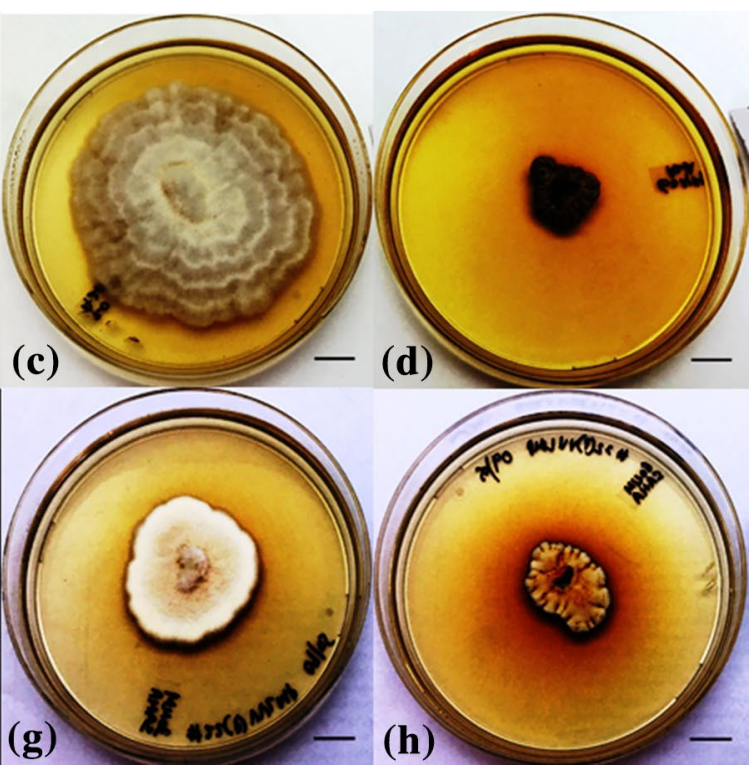

medium; f SAHA $10 \mu \mathrm{m}$ on PDA medium; g SAHA $30 \mu \mathrm{m}$ on PDA medium; h SAHA $60 \mu \mathrm{m}$ on PDA medium (Bar: $10 \mathrm{~mm}$ ) 


\section{Production and extraction of culture filtrates}

It was found that the volume of spent broth has reduced with the notable change in colour and characteristic smell of culture filtrates due to the production of secondary metabolites. The culture filtrates were filtered after 10 days of incubation using Whatman filter paper 4 . The biomass of culture filtrates was also recorded. It was found that the weight of the biomass increased up-to-the concentration of $10 \mu \mathrm{M}$ and then decreased from $20 \mu \mathrm{M}$ as the concentration increases. It was also observed that there is a positive correlation between the colony diameter and the dry weight of biomass (Supplementary Figs. 1, 2).

\section{Extraction and TLC of resveratrol from the endophytic fungus}

The cell-free filtrate of \#22(P) VVLPM was subjected to liquid-liquid extraction by ethyl acetate, and subsequently, the residue was reconstituted in methanol. The crude ethyl acetate fraction of \#22(P) VVLPM was subjected to different combinations of solvents to achieve proper separation.

The best separation of crude EA extract of \#22(P) VVLPM was observed in dichloromethane: Chloroform in the proportion of 5:5 which gave 5 different bands. The $R_{f}$ value of Band 1 to Band 5 was $0.125,0.25,0.28,0.325$, and 0.650 , respectively. The standard Resveratrol exhibited $R_{f}$ value of 0.650 which was similar to that of the $R_{f}$ value of Band 5 (Fig. 2) of crude ethyl acetate extract of \#22(P) VVLPM.

\section{HPLC for affirmation of resveratrol producing isolates}

Liquid chromatography is a prevalent method for qualitative and quantitative analysis. The standard graph of resveratrol in a concentration range of $0.1-1 \mathrm{mg} / \mathrm{mL}$ was constructed with a linearity of $\left(\mathrm{R}^{2}=0.9986\right)$. The good fitting curve was indicated in this range due to the higher value of regression coefficient. Further, the precision of fitting was confirmed based on the standard error (S.E.) at $95 \%$ confidence interval for the values of intercept $(5 \mathrm{E}+07)$ and slope $(-2 \mathrm{E}+06)$. Confirmation of fungal resveratrol was confirmed by HPLC analysis, which exhibited a symmetrical peak at retention time of $11.5 \mathrm{~min}$ on C18 reverse phase column similar to that of standard RESV (Fig. 3). The peak area versus RESV concentration, obtained in case of the standard RESV was used to estimate the quantity of fungal RESV present in the spent broth. Out of 26 epigenetic variants of \#22(P) VVLPM which were obtained after treatment with different concentrations of AZA and SAHA it was found that $10 \mu \mathrm{M}$ of AZA and $5 \mu \mathrm{M}$ SAHA exhibited highest Resveratrol concentration of $48.94 \mu \mathrm{g} / \mathrm{mL}$ and $52.32 \mu \mathrm{g} / \mathrm{mL}$ respectively as compared to control (35.43 $\mu \mathrm{g} /$

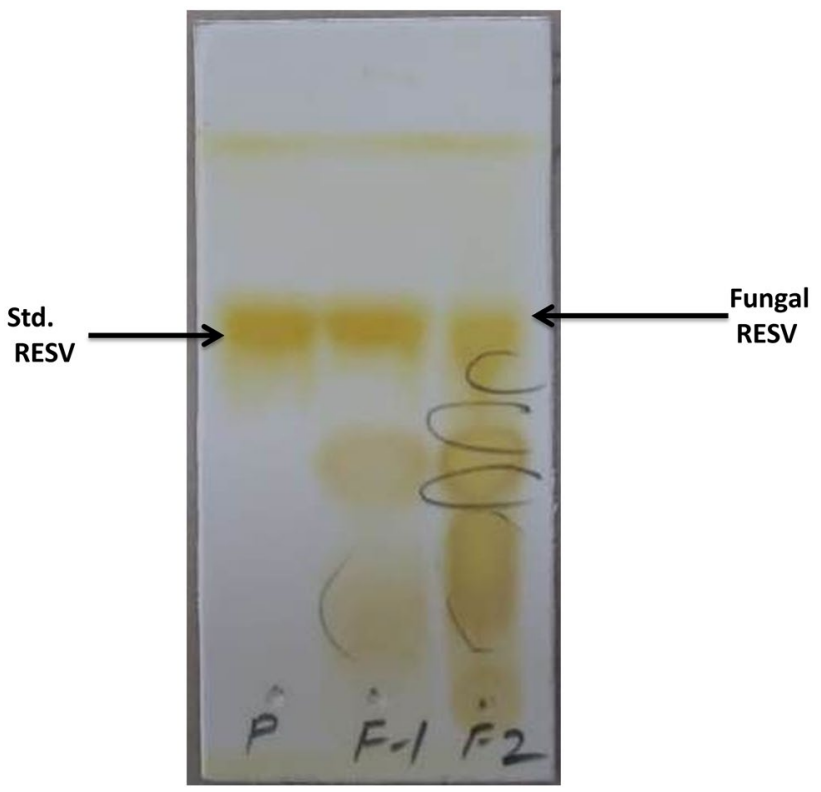

Fig. 2 TLC profile of crude extract of \#22(P) VVLPM using dichloromethane: chloroform solvent system, in the ratio of 5:5 as the mobile phase. The $R_{f}$ values of Band 1-4 was ranging between 0.650 and 0.125

$\mathrm{mL}$ ) and on increasing the concentration of AZA and SAHA a decrease in resveratrol concentration was observed (Table 1).

\section{LC-MS analysis}

For further confirmation of the presence of fungal resveratrol in the bioactive ethyl acetate residue obtained from the spent broth of \#22(P) VVLPM, LC-MS was carried out which revealed the presence of resveratrol. Further MS analysis revealed that the fungal resveratrol and standard resveratrol exhibited the same base peak at $228.1 \mathrm{~m} / \mathrm{z}$ (Fig. 4).

\section{Effect of AZA concentration on resveratrol production}

Through HPLC analysis it was found that there was a significant increase in resveratrol production when chemical elicitor AZA were added in the culture medium. An increase of $38.13 \%$ ( $48.94 \mu \mathrm{g} / \mathrm{mL}$ ) was recorded over the basal concentration of $35.43 \mu \mathrm{g} / \mathrm{mL}$ without any treatment in the case of AZA $10 \mu \mathrm{M}$ (Table 2). The decrease in concentration of resveratrol was also noted as compared to control after the treatment of AZA at the concentration of $10 \mu \mathrm{M}$ (Table 2).

\section{Effect of SAHA concentration on resveratrol production}

Through HPLC analysis it was found that there was a significant increase in resveratrol production when 

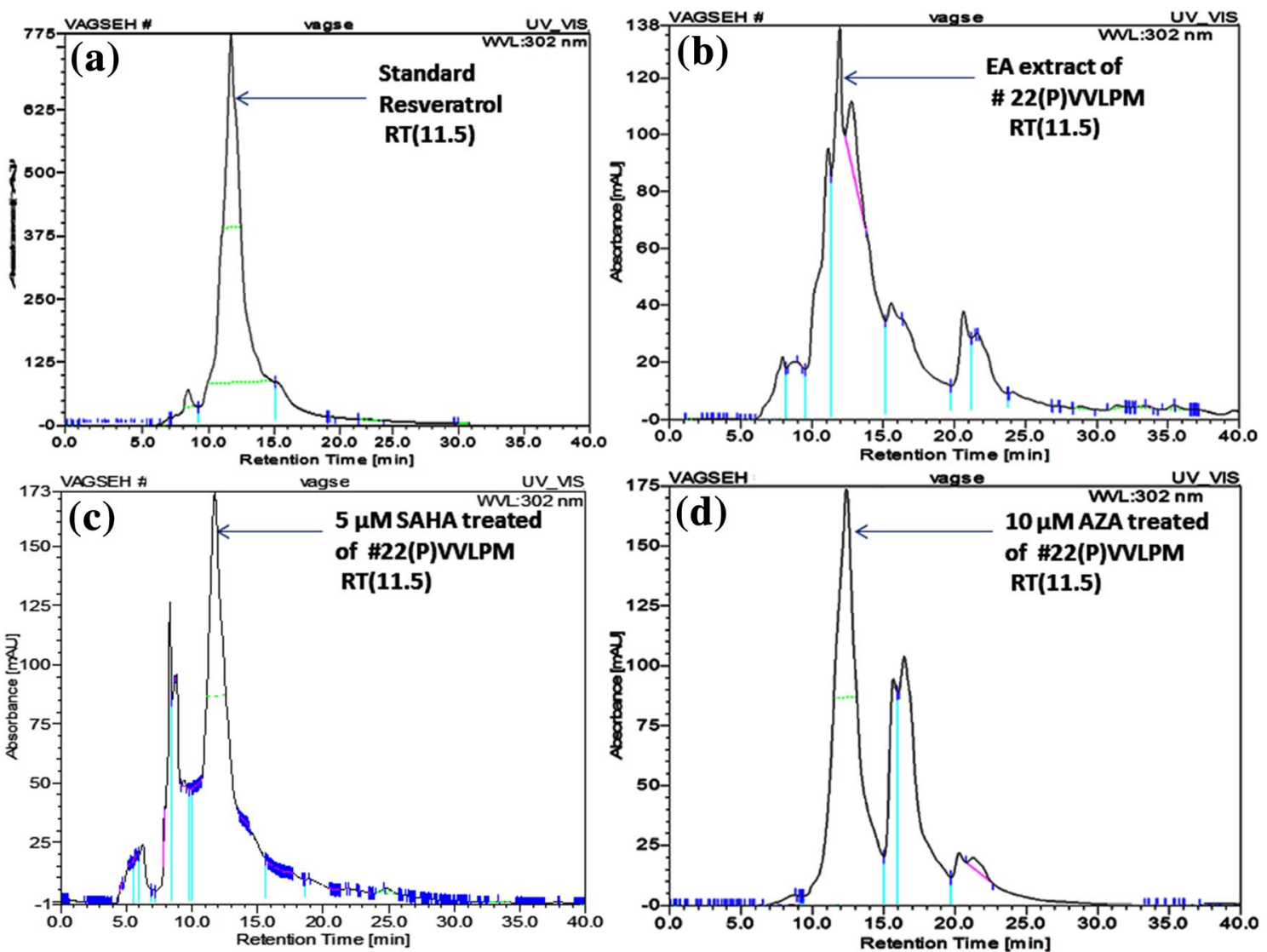

Fig. 3 HPLC-UV ${ }_{302 \mathrm{~nm}}$ chromatogram of a Standard resveratrol solution $(0.1-1 \mathrm{mg} / \mathrm{mL}) \mathrm{RT}(11.5)$, b ethyl acetate extract of crudefungal resveratrol from \#22(P)VVLPMRT(11.5), c $5 \mu \mathrm{m}$ SAHA treated of \#22(P) VVLPM RT(11.5), d $10 \mu \mathrm{m}$ AZA-treated of \#22(P) VVLPM RT(11.5)

Table 1 Morphological characteristics of the epigenetic variants of Xylaria psidii as compared to the wild \#22(P) VVLPM strain

\begin{tabular}{|c|c|c|c|}
\hline Characteristics & Wild (\#22(P) VVLPM) & AZA $(10 \mu \mathrm{m})$ & SAHA $(5 \mu \mathrm{m})$ \\
\hline Diameter (mm) & $54.5 \pm 0.14$ & $56.5 \pm 0.37$ & $55 \pm 0.61$ \\
\hline Colony color & $\begin{array}{l}\text { White velvety filamentous mycelia } \\
\text { growth, produces red wine colour }\end{array}$ & $\begin{array}{l}\text { A white velvety filamentous colony with } \\
\text { a red wine colour. Pink pigment around } \\
\text { the center of the growth }\end{array}$ & $\begin{array}{l}\text { A white velvety filamentous colony with } \\
\text { dark red wine colour. Pink pigment } \\
\text { around the center of the growth }\end{array}$ \\
\hline Color (base) & Red-wine color & $\begin{array}{l}\text { Red-wine color with pink pigmentation } \\
\text { around the center of the growth }\end{array}$ & $\begin{array}{l}\text { Red-wine color with pink pigmentation } \\
\text { around the center of the growth }\end{array}$ \\
\hline Margin & Smooth margin & Cottony smooth margin & Cottony smooth margin \\
\hline Odour & Fruity smell & Phenolic smell (Sweet and Terry) & Phenolic smell (Sweet and Terry) \\
\hline Dry weight (gm/L) & $12.43 \pm 0.65$ & $15.57 \pm 0.95$ & $16.51 \pm 1.12$ \\
\hline $\begin{array}{l}\text { Concentration of } \\
\text { RESV }(\mu \mathrm{g} / \mathrm{mL})\end{array}$ & $35.43 \pm 0.16$ & $48.94 \pm 0.33$ & $52.32 \pm 0.24$ \\
\hline
\end{tabular}

The results presented are a compilation of data from at least three cultures of each organism. Numerical values are mean \pm SD

chemical elicitor SAHA were added in the culture medium. An increase of $47.67 \%(52.32 \mu \mathrm{g} / \mathrm{mL})$ was recorded over the basal concentration of $35.43 \mu \mathrm{g} / \mathrm{mL}$ without any treatment in the case of SAHA $5 \mu \mathrm{M}$ (Table 2). A decrease in concentration of resveratrol was also noted as compared to control after the treatment of SAHA at the concentration of $5 \mu \mathrm{M}$ (Table 2).

\section{Identification of resveratrol producing a fungal isolate}

\section{Classical morphotaxonomy}

The identification of resveratrol producing endophytic fungus Xylaria psidii (\#22(P) VVLPM) was done on the basis of 

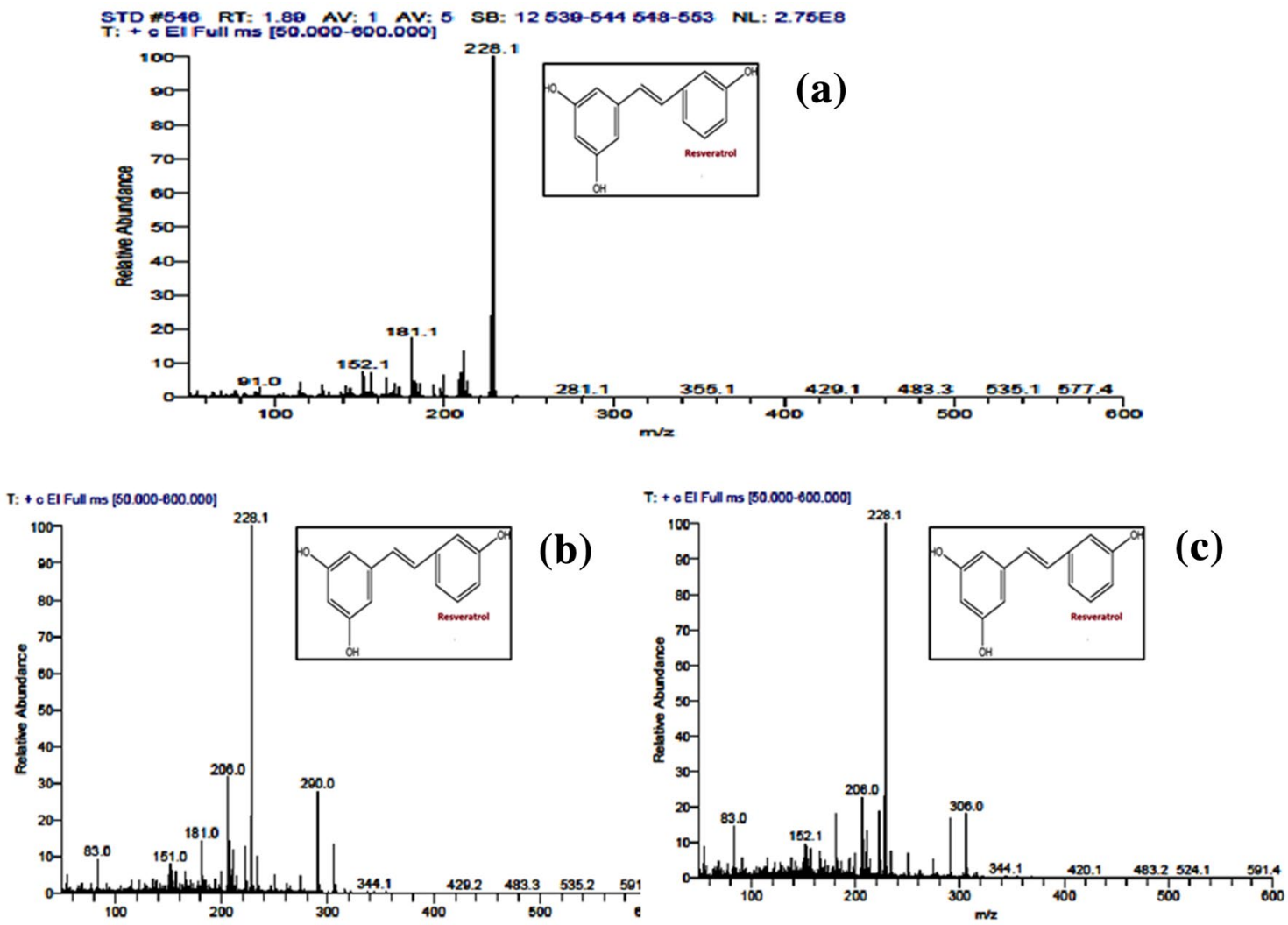

Fig. 4 Mass spectrometric analysis of a standard resveratrol, b fungal resveratrol $5 \mu \mathrm{m}$ SAHA treated of \#22(P) VVLPM, c fungal resveratrol $10 \mu \mathrm{m}$ AZA-treated of \#22(P) VVLPM

Table 2 The concentration of RESV and antioxidant activity of top AZA and SAHA epigenetic modifiers of \#22(P) VVLPM

\begin{tabular}{lllllll}
\hline Treatment & $\begin{array}{l}\text { Conc. of } \\
\text { RESV }(\mu \mathrm{g} / \\
\mathrm{mL}) *\end{array}$ & $\begin{array}{l}\text { \%increase or } \\
\text { decrease }(\%)\end{array}$ & DPPH $(\% \mathrm{FRS})^{*}$ & TEAC $(\% \mathrm{FRS}) *$ & \multicolumn{2}{c}{$\%$ increase or decrease } \\
\cline { 5 - 7 } & & & & DPPH (\%) & TEAC (\%) \\
\hline Control & $35.43 \pm 0.16$ & - & $19.26^{\mathrm{f}} \pm 0.48$ & $52.86^{\mathrm{f}} \pm 0.22$ & & \\
Standard & - & - & $60.05^{\mathrm{a}} \pm 1.65$ & $72.01^{\mathrm{b}} \pm 0.94$ & & \\
AZA 3 & $35.01 \pm 0.33$ & -1.19 & $23.83^{\mathrm{e}} \pm 0.49$ & $55.18^{\mathrm{e}} \pm 0.30$ & 23.73 & 4.39 \\
AZA 5 & $37.72 \pm 0.74$ & 6.46 & $25.57^{\mathrm{de}} \pm 0.32$ & $60.31^{\mathrm{d}} \pm 0.27$ & 32.76 & 14.09 \\
AZA 10 & $\mathbf{4 8 . 9 4} \pm \mathbf{0 . 3 3}$ & $\mathbf{3 8 . 1 3}$ & $\mathbf{3 0 . 9 2}^{\mathrm{c}} \pm \mathbf{0 . 7 4}$ & $\mathbf{7 0 . 8 3}^{\mathrm{b}} \pm \mathbf{0 . 6 5}$ & $\mathbf{6 0 . 5 4}$ & $\mathbf{3 4 . 0 0}$ \\
SAHA 5 & $\mathbf{5 2 . 3 2} \pm \mathbf{0 . 2 4}$ & $\mathbf{4 7 . 6 7}$ & $\mathbf{3 3 . 8 2}^{\mathbf{b}} \pm \mathbf{0 . 2 8}$ & $\mathbf{7 4 . 2 8}^{\mathrm{a}} \pm \mathbf{0 . 2 6}$ & $\mathbf{7 5 . 6 0}$ & $\mathbf{4 0 . 5 2}$ \\
SAHA 10 & $41.10 \pm 0.80$ & 16.00 & $29.78^{\mathrm{c}} \pm 0.17$ & $63.97^{\mathrm{c}} \pm 0.20$ & 54.62 & 21.02 \\
SAHA 20 & $32.65 \pm 0.72$ & -7.85 & $27.19^{\mathrm{d}} \pm 0.30$ & $59.30^{\mathrm{d}} \pm 0.46$ & 41.17 & 12.18 \\
\hline
\end{tabular}

Bold signifies the treatment wherein there was an enhancement in the resveratrol production by different epigenetic modifiers

*Data presented are the mean \pm standard deviation of three replicates. Means with different superscript letters are different by Tukey's post hoc test $(\mathrm{p}<0.05)$ its specific morphological and reproductive characteristics. Colonies of \#22(P) VVLPM on PDA produced wine red colour and orange colour (Fig. 5a). The colonies were moderately growing $(54 \pm 2 \mathrm{~mm})$, velvetenious white filamentous colonies with curly margins and radial crevices, floccose to downy colonies on different media after 30 days of incubation with $12 \mathrm{~h}$ photoperiod (Fig. 5a-d). Young colonies are usually white by aerial mycelium becoming red or orange due to its red pigment exudation (Fig. 5a, b).

Though the selected fungal isolate was cultivated on diverse media, it remained in vegetative state i.e. did not produce any reproductive structure like stromata, conidia, conidiogenous cells or ascospores after 2-9 weeks of incubation (Fig. 5a-d). Further, the isolate did not sporulate 


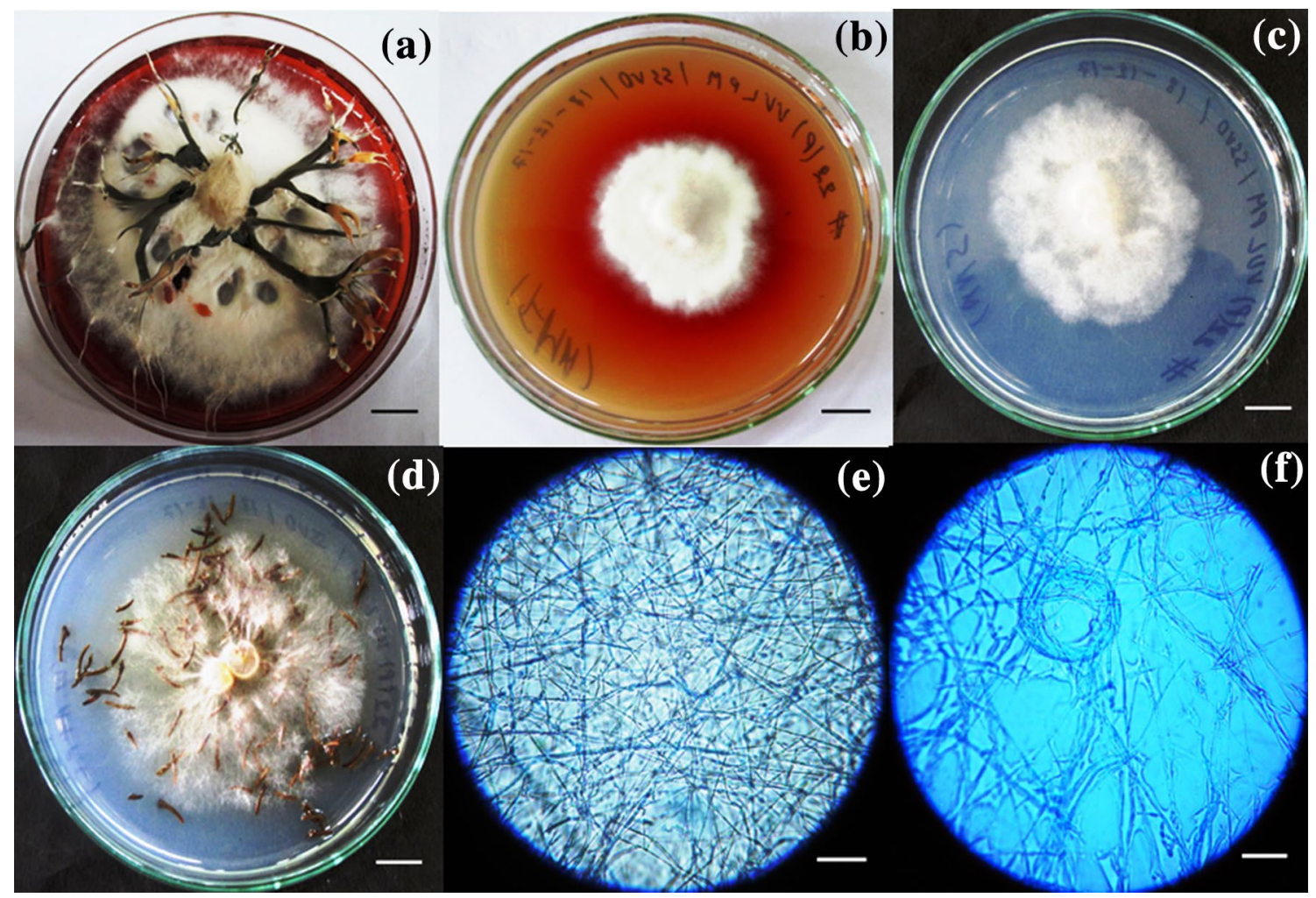

Fig. 5 Colony morphology and microscopic features of \#22(P) VVLPM (Xylaria sp). a PDA (pH 7) Red wine in colour, b Over FMA Media Reddish Brown in color, c, $\mathbf{d}$ Over SNA and PLA Media

even after providing stress conditions like incubation under complete darkness and ultraviolet radiation, but it could be identified by their specific stromata (Fig. 5a). Stromata are upright, 4-5 cm long, branched or unbranched, single or in clusters and extended to the fertile cylindrical or conical apex (Fig. 5a). Further identification using molecular technique revealed that the fungus belongs to the Xylaria sp.

\section{Molecular identification of resveratrol producing fungus}

The resveratrol producing endophytic fungi were initially identified using morphotaxonomic studies; however, their final identification was confirmed by carrying out the molecular phylogeny based on ITS sequences. BLAST analysis of ITS sequence of \#22(P) VVLPM exhibited a close homology with Xylaria psidii. However, to reconfirm a Maximum likelihood tree based upon Tamura and Nei model was prepared comprising of homologous sequences and ITS sequence of \#22(P) VVLPM. In this phylogenetic tree \#22(P) VVLPM clustered Xylaria psidii isolate SUT124 in clade I. Hence from morphological as well as phylogenetic analysis \#22(P) VVLPM was assigned the name Xylaria psidii (Fig. 6). The ITS sequence of \#22(P) VVLPM has been submitted in GenBank with accession no. MH142837. white in colour, e, f microscopic feature on SNA and PLA. Bars: (ad) $10 \mathrm{~mm} ;(\mathbf{e}, \mathbf{f}) 10 \mu \mathrm{m}$. (Color figure online)

\section{Biological assays}

\section{Antioxidant assays}

Free radical damage has been implicated in pathogenic infections, inflammatory response, cardiovascular disorders, ageing and autoimmune disorders like rheumatoid arthritis. Different in vitro assays were used to assess the antioxidant activity. In the present study the culture filtrate of Xylaria psidii was evaluated for its antioxidant potential activity using DPPH and ABTS assays. The best activity and percentage of free radical scavenging was observed in concentration $10 \mu \mathrm{M}$ AZA and $5 \mu \mathrm{M}$ SAHA, after that there was decline in free radical scavenging activity when we increase the concentration of AZA and SAHA.

\section{DPPH scavenging assay}

There was a statistically significant difference in the in vitro DPPH scavenging activity among the different fungal extracts by one way ANOVA. It was observed that the DPPH scavenging activity was significantly enhanced in the ethyl acetate extract of spent broth treated with $10 \mu \mathrm{M}$ AZA and $5 \mu \mathrm{M}$ of SAHA exhibiting the highest 
Fig. 6 Maximum Likelihood tree based on the ITS1-5.8SITS2 region. The percentage of replicate trees in which the associated taxa clustered together in the bootstrap test (1000 replicates)

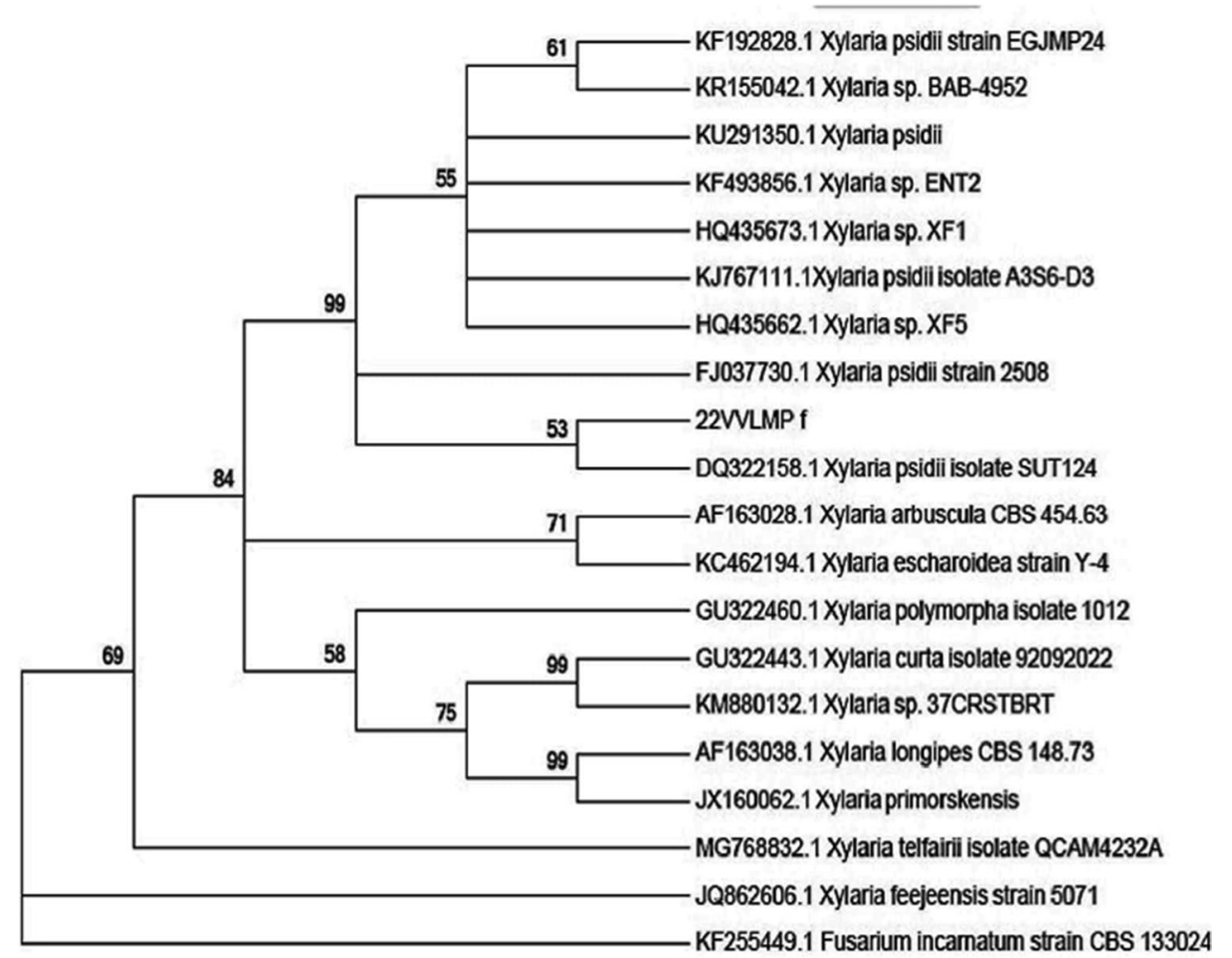

$\%$ free radical scavenging activity, i.e., $30.92 \pm 0.74$ and $33.82 \pm 0.28$. It was also observed that there was significant positive correlation between DPPH scavenging assay and resveratrol concentration because they both were highest at $10 \mu \mathrm{M}$ AZA and $5 \mu \mathrm{M}$ of SAHA. A similar correlation was observed by the resveratrol production, fungal biomass and diameter. The resveratrol was taken as standard. Also, a significant increase in \% free radical scavenging was observed as compared to wild strain whose $\%$ free radical scavenging activity was $19.26 \pm 0.48$ (Fig. 7c, d) (Table 2).

\section{Trolox equivalent antioxidant capacity (TEAC) assay}

In the in vitro TEAC assay a significant difference was observed in the fungal extracts by one way ANOVA.

It was observed that the TEAC was significantly enhanced in the ethyl acetate extract of spent broth treated with $10 \mu \mathrm{M}$ AZA and $5 \mu \mathrm{M}$ of SAHA which also exhibited the highest $\%$ free radical scavenging activity, i.e., $70.83 \pm 0.65$ and $74.28 \pm 0.26$ in the epigenetic variants of \#22(P) VVLPM which was more as compared to control $(52.86 \pm 0.22)$ (Fig. 7a, b) (Table 2). In case of TEAC here too positive correlation between TEAC scavenging assay, resveratrol concentration as well as biomass and diameter.

\section{Stability studies}

To determine the stability of the epigenetic mutants AZA $10 \mu \mathrm{M}$ and SAHA $5 \mu \mathrm{M}$ the mutated culture was subcultured up to 5 generations. The concentration of resveratrol was further analysed by using HPLC. It was observed that even after five generations the concentration of resveratrol produced by the mutant AZA $10 \mu \mathrm{M}$ and SAHA $5 \mu \mathrm{M}$ did not decrease significantly.

\section{Discussion}

Ever since the discovery of "Taxol" producing endophytic fungus Taxomyces andreanae from Taxus brevifolia, led the foundation for exploiting endophytic fungi as a novel source of biologically active secondary metabolites. Endophytic fungi have been immensely explored and exploited for the production of putative phytochemicals such as Taxol [35], Camptothecin [36], Podophyllotoxin [37], deoxypodophyllotoxin [36] and Vincristine [38]. Apart from being a potential source of putative phytochemicals, endophytic fungi also produce an array of bioactive moieties which are expressed in response to biotic and abiotic stresses to which plant is exposed from time to time [36]. Recent advancements in the fungal molecular genetics have established that fungi have many cryptic genes (phenotypically silent or unexpressed 

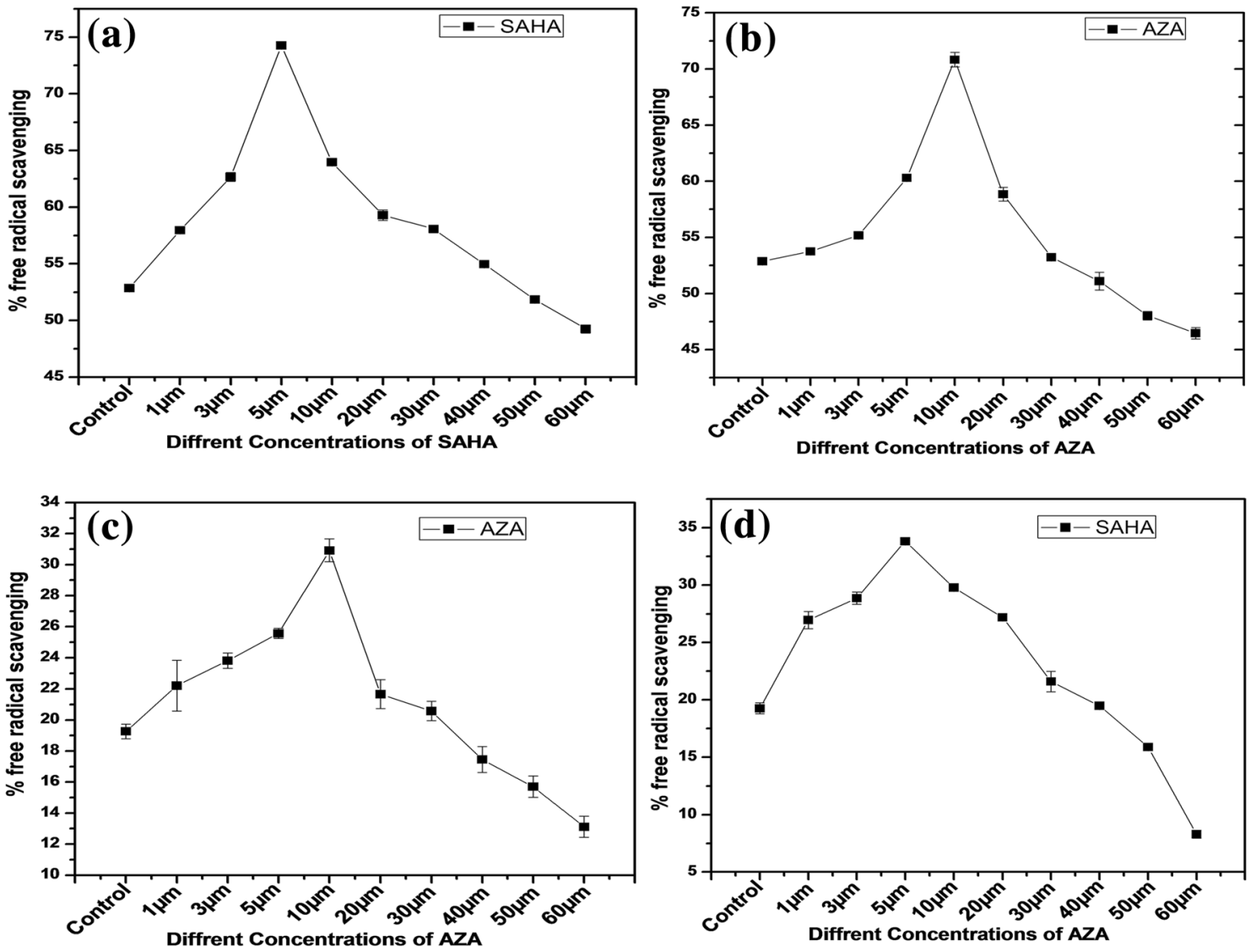

Fig. 7 Antioxidant activity of Xylaria psidii treated with different concentrations of AZA and SAHA using DPPH, ABTS assay, a ABTES AZA, b ABTES SAHA, c DPPH AZA, d DPPH SAHA

gene). These genes can be expressed by epigenetic modifiers like microbial and chemical elicitors, precursors, and through epigenetic modifications which leads to enhancement of novel secondary metabolite that could be exploited as a nutraceutical, pharmaceutical or in agrochemical industries [39, 40].

Epigenetic modifiers such as HDAC inhibitors (SAHA) and DMNTs (AZA) inhibitors represent an exciting chemical tool to express a cryptic or silent gene which is unexpressed under standard laboratory condition. Earlier the successful attempt of epigenetic modulation have been made using 5- azacytidine in mycodiesel producing endophytic fungus Hypoxylon sp. (CI-4), producing a vast number of volatile organic compounds, including 1,8-cineole, 1-methyl1,4-cyclohexadiene, and cyclohexane, 1,2,4-tris(methylene), which was selected as a candidate for the modulation of VOC production [39]. Li et al. [41] performed the co-culturing experiment of endophytic fungi Camporesia sambuci (FT1061) and Epicoccum sorghinum (FT1062) and reported a new $\mathrm{N}$-methoxypyridone analog, together with four known compounds. All these research have suggested that microbes have many genes which remain unexpressed under standard laboratory condition, and they need some epigenetic modifiers to activate these genes, leading to enhancement of novel secondary metabolites.

Resveratrol is natural polyphenolic stilbene, first identified as a significant lead compound of the French paradox which is related to its antioxidant potential, it is also reported for its multifarious application in various diseases like neurodegenerative disorder, cardiovascular disease, and also can promote the longevity of Saccharomyces cerevisiae. Due to these reasons, resveratrol is now widely used as a nutraceutical and in cosmetics [25, 42]. Xylaria psidii (\# 22(P) VVLPM) is a member of family Xylariales, though Xylaria $\mathrm{sp}$. has been previously reported from Vitis vinifera $[23,43]$. In the current research, a study was performed for enhancement of resveratrol production via using a different concentration of chemical elicitor in free fermentative medium to modulate the secondary metabolite production.

Thin layer chromatography is routinely used for separation and identification of compounds in a mixture which is generally carried out by using a standard along with the mixture to be resolved. Our study shows a similar retention factor of our fungal resveratrol to that of standard resveratrol 
(plant derived), i.e. 0.65. HPLC analysis further played a crucial role for the identification as well as quantification of resveratrol. HPLC analysis I revealed that RESV concentration was maximum and enhanced in the case of treatment with $5 \mu \mathrm{M}$ SAHA and by $10 \mu \mathrm{M}$ AZA followed by $10 \mu \mathrm{M}$ SAHA and $5 \mu \mathrm{M}$ AZA. In earlier reports, Colletotrichum gloeosporioides an endophytic fungus, was also reported to have an increase in cryptic compounds as well as their antimicrobial potential by using epigenetic modifiers, grape extract and turmeric extracts [17].

Endophytic fungi are famed for their antimicrobial as well as antioxidant potential [44]. The fungal resveratrol producing endophytic fungus \# 22(P) VVLPM in our study exhibited strong antioxidant potential. After treatment with different concentration of chemical elicitor like AZA and SAHA, a significant increase in antioxidant potential was obtained. In the case of DPPH increase in scavenging potential was found as compared to wild strain. Treatment with $5 \mu \mathrm{M}$ SAHA and by $10 \mu \mathrm{M}$ AZA was showing strong antioxidant potential among all epigenetic variants as compared to wild strain. In the case of TEAC also same trend as in the case of DPPH was obtained, whereas in the case of TPC and TFC an increment was observed in fungal samples treated with $3 \mu \mathrm{M}$ AZA and SAHA, $5 \mu \mathrm{M}$ AZA and SAHA, $10 \mu \mathrm{M}$ AZA and SAHA when compared to \#22(P) VVLPM control. Khanduja and Bhardwaj [45] in their study found that RESV showed stronger antioxidant potential than Catechin, Myricetin, and Fisetin. Shrikanta et al. [44] also observed antioxidant property which was attributed due to the presence of RESV in grapes and jamun.

Epigenetic modifiers such as HDAC inhibitors (SAHA) and dMNTs (AZA) inhibitors represent an exciting chemical tool to express a cryptic or silent gene which is unexpressed under standard laboratory condition. In the present study, the effect of two different epigenetic modifiers, i.e., HDAC inhibitors (SAHA) and dMNTs (AZA) inhibitors on the metabolic profile of Xylaria psidii (\#22(P) VVLPM) was studied. A significant effect on the secondary metabolite production was observed in HPLC profiles of the extract obtained after epigenetic induction when compared to extract obtained without addition of epigenetic modifiers. An HPLC and LC-MS spectrum shows an enhancement of $47.67 \%(52.32 \mu \mathrm{g} / \mathrm{mL})$ in case of SAHA $5 \mu \mathrm{M}$ and $38.13 \%$ $(48.94 \mu \mathrm{g} / \mathrm{mL})$ in case of AZA $10 \mu \mathrm{M}$, resveratrol concentration which was earlier present in very less amount $(35.43 \mu \mathrm{g} /$ $\mathrm{mL}$ ) in the crude ethyl acetate extract. A similar observation was made by some other researchers as carried out by Lopes et al. [46] wherein they used a range of epigenetic modifiers on Nigrospora sp. SS67 and they found that epigenetic modifiers increase the production of the secondary metabolites. Establishment of a high producing endophytic epigenetic mutant strain for industrial production of resveratrol is a genuine metabolic engineering challenge. All these studies vigorously advocate that fungi also have many genes like other eukaryotic microbes which remain cryptic under normal lab conditions, and need some epigenetic modifiers to activate fungal gene transcription, leading to the fungal strain improvement for production of known as well as novel secondary metabolites.

\section{Conclusion}

Considering the increased demand for resveratrol in pharmaceutical, food as well as cosmetic industries the enhancement of resveratrol production, using the epigenetic modifiers such as HDAC inhibitors (SAHA) and dMNTs (AZA) inhibitors was found as a potent chemical tool for induction of cryptic gene in the endophytic fungus Xylaria psidii for enhancement of the resveratrol production as well as antioxidant potential. Activation of silenced genes was more efficient with HDAC inhibitors (SAHA) than with dMNTs (AZA) inhibitors. This method is more effective than others as it is cost-effective, reliable supply and high purity as compared to extraction from plant materials. The present study shows a positive correlation between resveratrol content and the antioxidant potential.

Acknowledgement The Authors thank Department of Biotechnology (DBT), Government of India, New Delhi, for financial assistance through Project N0-BT/PR9094/NDB/39/378/2013 and Department of Biotechnology and TIFAC-CORE (Centre of Relevance and Excellence), Thapar Institute of Engineering and Technology, Patiala, Punjab for providing the necessary infrastructure to carry out the research work.

Author contribution Prof. Sanjai Saxena conceived and designed the present study, while Vagish Dwibedi and Shreya Kalia performed all experiments, analyzed the data. Prof. Sanjai Saxena and Vagish Dwibedi jointly wrote the publication.

\section{Compliance with ethical standards}

Conflict of interest Authors declare no conflict of interest. The founding sponsors had no role in the design of the study; in the analyses, or interpretation of data; in the writing of the manuscript, and in the decision to publish the results.

\section{References}

1. Kasiotis KM, Pratsinis H, Kletsas D, Haroutounian SA (2013) Resveratrol and related stilbenes: their anti-aging and anti-angiogenic properties. Food Chem Toxicol 61:112-120

2. Lee TH, Seo JO, Baek SH, Kim SY (2014) Inhibitory effects of resveratrol on melanin synthesis in ultraviolet $\mathrm{B}$-induced pigmentation in Guinea pig skin. Biomol Ther 22(1):35

3. Zhang HW, Song YC, Tan RX (2006) Biology and chemistry of endophytes. Nat Prod Rep 23(5):753-771

4. Bradamante S, Barenghi L, Villa A (2004) Cardiovascular protective effects of resveratrol. Cardiovasc Drug Rev 22(3):169-188 
5. Jang M, Cai L, Udeani GO, Slowing KV, Thomas CF, Beecher CW et al (1997) Cancer chemopreventive activity of resveratrol, a natural product derived from grapes. Science 275(5297):218-220

6. Kundu JK, Surh YJ (2008) Cancer chemopreventive and therapeutic potential of resveratrol: mechanistic perspectives. Cancer Lett 269(2):243-261

7. Langcake P, Pryce RJ (1976) The production of resveratrol by Vitis vinifera and other members of the Vitaceae as a response to infection or injury. Physiol Plant Pathol 9(1):77-86

8. Burns J, Yokota T, Ashihara H, Lean ME, Crozier A (2002) Plant foods and herbal sources of resveratrol. J Agric Food Chem 50(11):3337-3340

9. Lijavetzky D, Almagro L, Belchi-Navarro S, Martínez-Zapater JM, Bru R, Pedreño MA (2008) Synergistic effect of methyl jasmonate and cyclodextrin on stilbene biosynthesis pathway gene expression and resveratrol production in Monastrell grapevine cell cultures. BMC Res Notes 1(1):132

10. Donnez D, Jeandet P, Clément C, Courot E (2009) Bioproduction of resveratrol and stilbene derivatives by plant cells and microorganisms. Trends Biotechnol 27(12):706-713

11. Venugopalan A, Srivastava S (2015) Endophytes as in vitro production platforms of high-value plant secondary metabolites. Biotechnol Adv 33(6):873-887

12. Strobel G, Daisy B (2003) Bioprospecting for microbial endophytes and their natural products. Microbiol Mol Biol Rev 67(4):491-502

13. Kobayashi S, Ding CK, Nakamura Y, Nakajima I, Matsumoto R (2000) Kiwifruits (Actinidia deliciosa) transformed with a Vitis stilbene synthase gene produce piceid (resveratrol-glucoside). Plant Cell Rep 19(9):904-910

14. Kiselev KV (2011) Perspectives for production and application of resveratrol. Appl Microbiol Biotechnol 90(2):417-425

15. Cherblanc F, Chapman-Rothe N, Brown R, Fuchter MJ (2012) Current limitations and future opportunities for epigenetic therapies. Future Med Chem 4(4):425-446

16. Cherblanc FL, Davidson RW, Di Fruscia P, Srimongkolpithak N, Fuchter MJ (2013) Perspectives on natural product epigenetic modulators in chemical biology and medicine. Nat Prod Rep 30(5):605-624

17. Sharma VK, Kumar J, Singh DK, Mishra A, Verma SK, Gond SK et al (2017) Induction of cryptic and bioactive metabolites through natural dietary components in an endophytic fungus Colletotrichum gloeosporioides (Penz.) Sacc. Front Microbiol 8:1126

18. Williams RB, Henrikson JC, Hoover AR, Lee AE, Cichewicz RH (2008) Epigenetic remodeling of the fungal secondary metabolome. Org Biomol Chem 6(11):1895-1897

19. Schulz B, Wanke U, Draeger S, Aust HJ (1993) Endophytes from herbaceous plants and shrubs: effectiveness of surface sterilization methods. Mycol Res 97:1447-1450. https://doi.org/10.1016/ S0953-7562(09)80215-3

20. Petrini O, Sieber TN, Toti L, Viret O (1993) Ecology, metabolite production, and substrate utilization in endophytic fungi. Nat Toxins 1(3):185-196

21. Gupta YK, Briyal S, Chaudhary G (2002) Protective effect of trans-resveratrol against kainic acid-induced seizures and oxidative stress in rats. Pharmacol Biochem Behav 71(1-2):245-249

22. Shi J, Zeng Q, Liu Y, Pan Z (2012) Alternaria sp. MG1, a resveratrol-producing fungus: isolation, identification, and optimal cultivation conditions for resveratrol production. Appl Microbiol Biotechnol 95(2):369-379

23. Dwibedi V, Saxena S (2018) Arcopilus aureus, a resveratrol-producing endophyte from Vitis vinifera. Appl Biochem Biotechnol 186:476-495

24. Babu SK, Kumar KV, Subbaraju GV (2005) Estimation of trans-resveratrol in herbal extracts and dosage forms by high-pe $\mathrm{Rf}_{\mathrm{f}}$ ormance thin-layer chromatography. Chem Pharm Bull 53(6):691-693

25. Wang DG, Liu WY, Chen GT (2013) A simple method for the isolation and purification of resveratrol from Polygonum cuspidatum. J Pharm Anal 3(4):241-247

26. Dincheva I, Badjakov I, Tsvetkov I, Dzhambazova T, Kondakova V, Batchvarova R (2011) GC-MS determination of secondary metabolites in red wine from Bulgarian wild grape (Vitis vinifera ssp. sylvestris. J Mt Agric Balkans 14(6):1331-1343

27. Ramirez-Lopez LM, DeWitt CA (2014) Analysis of phenolic compounds in commercially dried grape pomace by high-performance liquid chromatography-electrospray ionization mass spectrometry. Food Sci Nutr 2(5):470-477

28. Ellis MB, Ellis JP (1985) Microfungi on land plants. An identification handbook. Croom Helm Ltd., Kent

29. Barnett HL, Hunter BB (1998) Illustrated genera of imperfect fungi

30. Nagamani A, Kunwar IK, Manoharachary C (2006) Handbook of soil fungi. IK International, New Delhi

31. White TJ, Bruns T, Lee SJWT, Taylor JL (1990) Amplification and direct sequencing of fungal ribosomal RNA genes for phylogenetics. PCR Protoc 18(1):315-322

32. Tamura K, Stecher G, Peterson D, Filipski A, Kumar S (2013) MEGA6: molecular evolutionary genetics analysis version 6.0. Molecular Biol Evol 30(12):2725-2729

33. Ho R, Violette A, Cressend D, Raharivelomanana P, Carrupt PA, Hostettmann K (2012) Antioxidant potential and radical scavenging effects of flavonoids from the leaves of Psidium cattleianum grown in French Polynesia. Nat Prod Res 26:274-277

34. Re R, Pellegrini N, Proteggente A, Pannala A, Yang M, RiceEvans C (1999) Antioxidant activity was applying an improved ABTS radical cation decolorization assay. Free Radic Biol Med 26(9-10):1231-1237

35. Stierle A, Strobel G, Stierle D (1993) Taxol and taxane production by Taxomyces andreanae, an endophytic fungus of Pacific yew. Science 260(5105):214-216

36. Kusari S, Hertweck C, Spiteller M (2012) Chemical ecology of endophytic fungi: origins of secondary metabolites. Chem Biol 19(7):792-798

37. Eyberger AL, Dondapati R, Porter JR (2006) Endophyte fungal isolates from Podophyllum peltatum produce podophyllotoxin. $\mathrm{J}$ Nat Prod 69(8):1121-1124

38. Aly AH, Debbab A, Proksch P (2011) Fungal endophytes: unique plant inhabitants with grand promises. Appl Microbiol Biotechnol 90(6): 1829-1845

39. Ul-Hassan SR, Strobel GA, Booth E, Knighton B, Floerchinger C, Sears J (2012) Modulation of volatile organic compound formation in the mycodiesel-producing endophyte Hypoxylon sp. CI-4. Microbiology 158(2):465-473

40. Kumar J, Sharma VK, Singh DK, Mishra A, Gond SK, Verma SK et al (2016) Epigenetic activation of antibacterial property of an endophytic Streptomyces coelicolor strain AZRA 37 and identification of the induced protein using MALDI TOF MS/MS. PLoS ONE 11(2):e0147876

41. Li C, Sarotti AM, Yang B, Turkson J, Cao S (2017) A new $\mathrm{N}$-methoxypyridone from the co-cultivation of Hawaiian endophytic fungi Camporesia sambuci FT1061 and Epicoccum sorghinum FT1062. Molecules 22(7):1166

42. Jiménez JB, Orea JM, Ureña AG, Escribano P, De La Osa PL, Guadarrama A (2007) Short anoxic treatments to enhance transresveratrol content in grapes and wine. Eur Food Res Technol 224(3):373-378

43. Mostert L, Crous PW, Petrini O (2000) Endophytic fungi associated with shoots and leaves of Vitis vinifera, with specific reference to the Phomopsis viticola complex. Sydowia 52(1):46-58 
44. Shrikanta A, Kumar A, Govindaswamy V (2015) Resveratrol content and antioxidant properties of underutilized fruits. J Food Sci Technol 52(1):383-390

45. Khanduja KL, Bhardwaj A (2003) Stable free radical scavenging and antiperoxidative properties of resveratrol compared in vitro with some other bioflavonoids

46. Lopes AA, da Silva DB, Lopes NP, Pupo MT (2012) Epigenetic modulation changed the secondary metabolite profile in the endophyte Nigrospora sphaerica SS67. Planta Med 78(14):PL38
Publisher's Note Springer Nature remains neutral with regard to jurisdictional claims in published maps and institutional affiliations. 